\title{
Ampirik Potansiyel Evapotranspirasyon Tahmin Yöntemlerinin Değerlendirilmesi: Uygulama Konya Kapalı Havzası
}

\author{
Nermin ŞARLAK ${ }^{1}$ \\ Soner Çağatay BAĞÇACI ${ }^{2}$
}

\section{ÖZ}

Evapotranspirasyon, hidrolojik çevrimde kritik bir rol oynar. Ancak havza ve tarla ölçeğinde miktarının tahmini zordur. Bilim insanları, bu konuyu incelemek amacıyla yaygın erişilebilir ölçülmüş değiş̧kenlere dayanan tahminler sağlayan ampirik denklemler geliştirmişlerdir. Blaney-Criddle, Jensen-Haise, Makkink, Turc, Priestley-Taylor ve Hargreaves-Samani adlı altı ampirik yöntemin performansları, Konya Kapalı Havzası'ndaki beş istasyondan alınan günlük meteorolojik veriler kullanılarak FAO-56 Penman-Monteith yöntemi ile karşılaştırılmış ve tartışılmıştır. Turc, Hargreaves-Samani ve Priestley-Taylor yöntemlerinin FAO-56 Penman-Monteith'e alternatif olarak ön plana çıktığı sonucuna varılmıştır. Ayrıca, sulama sezonu dikkate alındığında Turc, altı yöntemden en iyisi olmuştur. Sadece günlük sicaklık verisine ihtiyaç duyan Hargreaves-Samani yönteminin bölge özelindeki performansının yadsınamayacak derecede başarılı olduğu vurgulanması gereken bir diğer noktadir.

Anahtar Kelimeler: Evapotranspirasyon, ampirik yöntemler, Konya Kapalı Havzası.

\section{ABSTRACT \\ The Assesment of Empirical Potential Evapotranspiration Methods: A Case Study of Konya Closed Basin}

Evapotranspiration plays a critical role in hydrologic cycle. However, it is difficult to estimate its quantification at basin and arable land scales. Scientists have developed array of empirical equations that provide estimates of it based on more readily measured quantities in order to analyze this issue. The performance of six empirical methods namely BlaneyCriddle, Jensen-Haise, Makkink, Turc, Priestley-Taylor and Hargreaves-Samani were

\footnotetext{
Not: Bu yazı

- Yayın Kurulu’na 20 Mart 2018 günü ulaşmıştır. 2 Ocak 2019 günü yayımlanmak üzere kabul edilmiştir.

- 31 Mart 2020 gününe kadar tartışmaya açıktır.

- DOI: $10.18400 /$ tekderg.408019

1 Karamanoğlu Mehmetbey Üniversitesi, İnşaat Mühendisliği Bölümü, Karaman - nsarlak@kmu.edu.tr https://orcid.org/0000-0003-3632-2725

2 Karamanoğlu Mehmetbey Üniversitesi, İnşaat Mühendisliği Bölümü, Karaman - scbagcaci@kmu.edu.tr https://orcid.org/0000-0002-2673-0234
} 
discussed comparing with FAO-56 Penman-Monteith method using daily meteorological data obtained from five stations in Konya Closed Basin. The results showed that Turc, Hargreaves-Samani ve Priestley-Taylor methods have come into prominence as an alternative to FAO-56 PM. Furthermore, Turc was best among the six methods when the irrigation season was considered. Another point to be emphasized is that the performance of Hargreaves-Samani method, which only needs daily temperature data, was undeniably successful in this region.

Keywords: Evapotranspiration, empirical method, Konya Closed Basin.

\section{GíRiș}

Hidrolojik çevrimin ölçülmesi en zor bileşeni olan Evapotranspirasyon (ET), terleme ile birlikte toprak, bitki örtüsü ve açık su yüzeyi bulunan alanlardan kaybolan toplam su miktarı olarak tanımlanmaktadır. Su kaybı bitki yüzeyinden terleme (transpirasyon), toprak ve açık su yüzeylerinden doğrudan buharlaşma yoluyla olmaktadır. Terleme bitkinin fotosentez yapabilmesi için gerekli olan karbondioksiti atmosferden temin ederken stomasını açtığı zaman maruz kaldığı bedel veya ceza olarak düşünülebilir [1]. Her iki su kaybını birbirinden ayırmak zor ve gereksiz olduğundan evapotranspirasyon terimi altında birleştirilmişlerdir.

Karasal alana düşen yağışın yaklaşık \%62'sinin ET yoluyla atmosfere geri döndüğü tahmin edilmektedir [2]. Tartışmaya yer bırakmayan sıcaklıktaki küresel artışın toplam su kayıplarına etkisi ancak en doğru şekilde tahmin edilen ET miktarlarının belirlenmesi ile mümkün olabilecektir. Tarla ölçeğinde bakıldığında ise, bitki su tüketiminin (sadece bitki kaplı yüzeylerden olan buharlaşma, terleme ve bitki tarafından kullanılan su) belirlenmesi geliştirilen toprak-su kaynakları projelerinin başarı temeli sayılmaktadır.

Gerek havza ölçeğinde gerekse tarla ölçeğinde bu kadar önemli olan toplam su kaybının ölçülmesi maddi olarak çok büyük yük teşkil etmekle birlikte, fiziki şartlar açısından da oldukça zordur. Buna karşılık, ET tahmini için günümüze kadar çok sayıda yöntem ve model geliştirilmiştir. Söz konusu çalışmalar deneysel, mikro-meteorolojik ve ampirik olarak üç başlık altında toplanabilir. Deneysel çalışmalarda tartılamayan ve tartılı lizimetre kullanılmaktadır. Uygulanması fiziksel açıdan zor ve pahalı olmasının yanı sıra, değişen arazi yapısındaki heterojenliklerden kaynaklı olarak birçok lizimetre düzeneği gerektirmesi ve sonuçlarının yerel olması yöntemin kısıtlamaları olarak sunulmaktadır [3, 4]. Buharlaşma tavası ile ET'nin ölçülmesi de deneysel yöntem olarak kabul edilebilir. Tavanın bulunduğu konuma ve bu konumun iklim özelliklerine bağlı birtakım katsayılarla çarpılarak potansiyel evapotranspirasyon (PET) hakkında çıkarımlar yapılabilmektedir [5]. Bu işlem ise lizimetreye göre daha az maliyetli olmasına rağmen arazideki veya daha büyük su kütlelerindeki buharlaşmaları tam olarak temsil edememektedir. Bowen oranı enerji dengesi, Eddy-Kovaryans ve Aerodinamik gibi mikro-meteorolojik yöntemler difüzyon yasasına dayanır. Yüksek konsantrasyondan düşük konsantrasyona hareket eden türbülanslı bir ortamdaki gaz molekülünün $\left(\mathrm{CO}_{2}\right.$ veya $\mathrm{H}_{2} \mathrm{O}$ gibi), rüzgâr hızının ve hava sıcaklığının düşey değişimini dikkate almaktadırlar [2]. Nem, sıcaklık ve düşey hız değişimlerini yüksek frekansta $\left(10 \mathrm{~s}^{-1}\right)$ bir araya getirip kayıt edebilme kapasitesine sahip sensörler kullanıldığında hiz profili veya atmosferik denge hakkında varsayımlarda bulunmaya gerek kalınmayacağından, bu yöntemlerden tahmin edilen ET değerleri doğru kabul edilmektedirler. Ancak, pahalı olmaları ve genellikle araştırma yapmak için seçilen nispeten 
daha küçük alanlar (1-2 hektar) için kullanılmaları yöntemlerin tercih edilebilirliğini kısıtlamaktadır. Son zamanlarda gelişen uydu teknolojileriyle birlikte, uzaktan algılama yöntemleriyle havza bazında gerçekleşen ET'nin miktarları tahmin edilmeye çalışılmaktadır. Fakat bu yöntemlerle alınan ölçümler arasındaki zaman adımlarının fazla olması, elde edilen uydu görüntülerinin çözünürlüğünün düşük olması ve bulutluluk, toz firtınaları gibi atmosferik olayların kızılötesi ölçümlerini imkânsız hale getirmesi bu yöntemlerin kullanılabilirliklerini azaltmaktadır [6]. Bu sebeplerden dolayı özellikle son 60-70 yıl içinde kütle-transferi, enerji dengesi ve her ikisinin beraber göz önüne alındığı yaklaşımlar ile meteorolojik gözlem verilerinden türetilen denklemler kullanılarak, PET'un tahmin edilmesi için ampirik yöntemler geliştirilmiştir [7]. Literatürde en çok kullanılan ampirik yöntemlerden Thornthwaite, Blaney-Criddle, Hamon, Romanenko, ve Hargreaves sicaklık değişkeni temelli; Makkink, Jensen-Haise, Priestly-Taylor, Doorenbos ve Pruitt ve Abtew radyasyon değişkeni temelli; Turc ve Hargreaves-Samani sıcaklık ve radyasyon değişkeni temellidir. Enerji bütçesi ve kütle-transferi (aerodinamik) denklemlerin kombinasyonuna dayalı açık yüzey buharlaşma denklemi Penman tarafından 1948 yılında geliştirilmiştir. Dünyanın pek çok yerinde yapılan çalışmalar geliştirilen denklemin açık yüzey buharlaşma tahmininde oldukça başarılı sonuçlar verdiğini gösterdiğinden, denklem bazı sabiteler kullanılarak bitki kaplı yüzeylerde de kullanılması için uyarlanmaya çalışılmıştır. PenmanMonteith (PM) bu çalışmalardan ilkidir [8]. Denklem enerji değişimine ve buna karşılık tekdüze bitki yüzeyinden oluşan gizli 1sı akısına (evapotranspirasyon) neden olan tüm parametreleri içermektedir [5]. Priestley ve Taylor, PM denklemini bazı değişkenlerinin etkisini bünyesine alan $\alpha(=1.26)$ katsayısı ile basitleştirmeye çalışmışlardır [9]. FAO-56 PM denklemi ise, referans bitki yüzeyinden oluşan ET'nin tahmini için geliştirilmiştir [5]. Lemeur ve Zhang, FAO-56 PM yöntemini Çin'de çorak iklim bölgesindeki Xinjiang nehir havzasına uygulamışlar ve su dengesi yaklaşımı ile elde ettikleri gerçek ET değerlerine en yakın sonuçların bu yöntemden elde edildiğini vurgulamışlardır [10]. Lopez-Urrea ve ark., İspanya'nın yarı-çorak iklim bölgesinde yer alan Albacete şehrinde tartılı lizimetre düzeneğinden ve zirai-meteoroloji istasyonundan aldıkları veriler ile yaptıkları çalışmada FAO-56 PM'in en doğru sonuç veren yöntem olduğunu ifade etmişlerdir [11]. Son on yıldan daha uzun süredir farklı bölgelerdeki kısa-yeşil-çim yüzeylerde değerlendirilen FAO-56 PM yöntemi, ölçüm değerlerine en yakın sonuçları tahmin edebilme kapasitesinden dolayı evrensel olarak standart PET yöntemi olarak kabul edilmektedir $[2,12]$.

Evapotranspirasyon konusunda geçmişten günümüze kadar pek çok çalışma yapılmıştır. Bu çalışmada, son yıllarda yapılan çalışmaların bazılarına üç grup altında değinilmiştir. Birinci grup çalışmalar, deneysel çalışmalardan gözlemledikleri veya referans olarak kullandıkları FAO-56 PM yöntemi ile daha az değişkene ihtiyaç duyan ampirik yöntemlerden hesapladıkları ET değerlerini kıyaslayarak çalışma alanları için en iyi tahmin yapan ama aynı zamanda daha az değişkene ihtiyaç duyan yöntemi önerme kaygısı taşımaktadırlar $[3,7,13$, $14,15,16,17,18,19,20,21,22]$. İkinci grup çalışmalar, uydu verilerini kullanılarak gerçek ET tahmin etme üzerinedir $[23,24,25]$. Üçüncü grup çalışmalarda ise yapay sinir ağları, bulanık mantık gibi yapay zekâ modelleri ile ampirik denklemler kıyaslanmış ve yapay zekâ modellerinin başarıları öne çıkarılmıştır [26, 27, 28]. Son zamanlarda gözlemlenen güneş radyasyonu ölçüm değerlerinde azalma (havadaki değişen partiküler madde konsantrasyonu, bulutluluk miktarının artması, rüzgâr hızının azalması gibi etmenlerden kaynaklanabilir), sıcaklık ve atmosferdeki $\mathrm{CO}_{2}$ miktarındaki artış ve ormanların yok olması buna karşılık şehirleşmenin artması ve sulak alanların azalması ile değişen arazi kullanımının çalışma 
alanları üzerindeki etkileri değişkenlik arz edeceğinden, ET’nin daha az değişken ile doğru tahmin edilme çabalarının devam etmesi kaçınılmazdır.

Bu çalışmada, ülkemizde tarıma önemli katkılar vermesine rağmen, ülke ortalamasının yarısı kadar yağış alan Konya Kapalı Havzasında oluşan evapotranspirasyonun potansiyel miktarı ampirik yöntemlerle tahmin edilmeye çalışılacaktır. Bu kapsamda yukarıda vurgulanmaya çalışıldığı gibi, verdiği sonuçların doğruluğu dünyanın farklı iklim tiplerine sahip birçok bölgesinde test edilmiş FAO-56 PM metodu ile ölçülmüş veri ihtiyacı daha az olan BlaneyCriddle, Jensen-Haise, Makkink, Turc, Priestley-Taylor ve Hargreaves-Samani yöntemlerinin bölge özelinde PET tahmin performansları değerlendirilmiştir. Konya Kapalı Havzası iklim koşullarına uygun bölgelerden türetilmemiş olan ampirik yöntemler, literatürde en çok rastlanılan yöntemler olmaları sebebiyle çalışmaya dahil edilmişlerdir.

\section{2. ÇALIŞMA SAHASI}

Konya Kapalı Havzası, İç Anadolu Bölgemizde 3651' ve 39²9' kuzey enlemleri ile $31^{\circ} 36^{\prime}$ ve $34^{\circ} 52^{\prime}$ doğu boylamları arasında yer almaktadır. 5,5 milyon hektarlık yüzölçümü ile Türkiye'nin yaklaşık \%7'sini teşkil eden havza, Türkiye'nin tahıl ambarı olarak bilinmektedir. Aksaray, Karaman, Konya, Niğde illerinin merkezleri ve bu illere bağlı olan ilçelerin yanı sıra Ankara, Antalya, Isparta, Mersin, Nevşehir illerine bağlı ilçelerin bir kısmı da havza sınırı içerisinde yer almaktadır. Yarı çorak iklim özelliklerine sahip olan havzaya, yıllık ortalama olarak yaklaşık $315 \mathrm{~mm}$ yağış düşmekte ve ortalama sıcaklıklar yine yıllık bazda $-0,4^{\circ} \mathrm{C}$ ile $23^{\circ} \mathrm{C}$ arasında değişmektedir [29, 30]. Havza, ülkemizde kullanılabilir yüzey suyu kaynaklarının \%2'sini, yeraltı suyu kaynaklarının ise yaklaşık \%17'sini bünyesinde barındırmakta ve havzadaki toplam yıllık kullanılabilir su kaynağının yaklaşık \%90'1 tarımsal sulama için harcanmaktadır [30].

Çalışmada kullanılan minimum, maksimum ve ortalama sıcaklık $\left({ }^{\circ} \mathrm{C}\right)$, toplam global güneş radyasyonu $\left(\mathrm{cal} / \mathrm{cm}^{2}\right)$, ortalama rüzgâr hızı $(\mathrm{m} / \mathrm{s})$ ve ortalama nispi nem $(\%)$ günlük verileri Meteoroloji Genel Müdürlüğü'nün Çizelge 1'de belirtilen gözlem istasyonlarından temin edilmiştir.

Çizelge 1 - Seçilen meteorolojik gözlem istasyonlarının yeri ve karakteristik özellikleri

\begin{tabular}{cccccc} 
İstasyon Adı & İstasyon No & Enlem & Boylam & Rakım & Çalışma Periyodu \\
\hline Aksaray & 17192 & 38,37 & 34 & 970 & $2000-2015$ \\
Ereğli & 17248 & 37,53 & 34,05 & 1046 & $2000-2010$ \\
Karaman & 17246 & 37,19 & 33,22 & 1018 & $2000-2014$ \\
Karapınar & 17902 & 37,71 & 33,53 & 996 & $2000-2010$ \\
Niğde & 17250 & 37,96 & 34,68 & 1211 & $2000-2010,2013-2015$
\end{tabular}

Meteorolojik gözlem istasyonlarının 2000-2015 yılları arası verileri temin edilmiş olmasına rağmen, bazı değişkenlerde önemli derecede eksik veri bulunduğundan hesaplamalara dâhil edilememiştir. Aksaray istasyonu 2004 yılı Ekim ve 2008 yılı Nisan aylarında; Ereğli 
istasyonu 2000 yılı Mart ayında günlük toplam global güneş radyasyonu ölçümleri bulunmadığından, hesaplamalarda kullanılmamıştır. Niğde istasyonu 2011-2012 yıllarında; Ereğli ve Karapınar istasyonlarında ise 2011-2015 yılları arasında günlük toplam global güneş radyasyonu ölçümleri bulunmadığından bu yıllardaki veriler hesaplamalara dahil edilememişlerdir. Karaman istasyonunda ise 2015 yılında, günlük ortalama rüzgâr hızı ölçümlerinin \%35'i eksik olduğundan bu yıldaki hiçbir veri hesaplamalarda kullanılamamıştır. Kalan dönemlerdeki eksik veriler, bütün gözlem istasyonları için toplam ölçümlerin \%15'ini geçmediğinden, çalışılan ayın kalan günlerindeki gözlem verilerinin ortalaması alınarak tamamlanmıştır. Konya H. istasyonu verisi çalışmaya dahil edilmek istenmiş ancak verisindeki eksikliklerin fazla olmasından dolayı çalışmaya dahil edilememiştir. Kullanılan verilerin güvenilirliğini ölçmek için parametrik olmayan KruskalWallis testi uygulanmış ve verilerin \%95 önem seviyesinde homojen olduğu saptanmıştır.

\section{YÖNTEM}

\section{Blaney-Criddle (BC)}

1942 yılında Blaney ve Morin tarafından önerilmiş ve en son 1952 yılında Blaney ve Criddle tarafından uyarlanarak bilinen halini almıştır [31]. Önerilen bitki su tüketim miktarı (v $($ aylık $)=\mathrm{kf}$ ve $\mathrm{V}($ mevsimlik $)=$ toplam $\mathrm{kf}=\mathrm{KF})$ bitki su tüketim katsayılarının (k) elde edilmesi için geliştirilmiştir. Bitki su tüketim miktarını doğru bir şekilde belirlemede göz önüne alınması gereken pek çok faktör bulunmasına rağmen, Blaney ve Criddle sıcaklık ve güneşlenme (foto peryot) süresinin bitki büyümesinde etkili olan en önemli iklim faktörü olduğunu belirtmişlerdir. Bitki su tüketiminin fotosentez yapabilme şansı ile değiştiği bilindiğinden, enlem ile değişen güneşlenme süresinden hesaplanan yıllık gündüz saatlerinin aylık yüzdesi (p) geliştirilen denkleme dahil edilmiştir. Sonuç olarak ET tahmin etmek için geliştirilen denklemde sıcaklık, gün uzunluğu ve kaynağına bakılmaksızın (yağış, sulama suyu veya yeraltı suyu olabilir) mevcut su muhtevası değişkenleri kullanılmıştır. Aylık iklim parametresi, f aşağıdaki eşitlikten hesaplanmaktadır:

$\mathrm{f}=\mathrm{T}^{*} \mathrm{p} / 100$

eşitlikte T ortalama aylık sıcaklık $\left({ }^{\circ} \mathrm{C}\right)$, p ise yıllık gündüz saatlerinin aylık yüzdesidir. Yöntemde yeterli su bulunduğu kabulü ile bitki su tüketiminin bu parametre ile doğru orantılı olarak değiştiği varsayılmıştır. Bir diğer varsayım da toprak veriminin her yerde aynı olduğudur. Metrik birim sisteminde denklem aşağıdaki şekilde ifade edilmiştir:

$\mathrm{v}=\mathrm{kp}\left(\frac{45.7 T+813}{100}\right)=$ aylık tüketim miktarı $(\mathrm{mm})$

Amprik olarak belirlenmiş bitki su tüketim katsayısı (k) kullanıldığında, yetiştiği ortamda söz konusu bitki için toplam su tüketim miktarı belirlenebilmektedir. Yöntem basit olmasına karşın, pek çok araştırmacı tarafından çorak (nemli) bölgelerde ölçülmüş ET değerlerinin altında (üstünde) sonuç verdiği tespit edilmiştir [32]. 


\section{Jensen -Haise (JH)}

Blaney - Criddle yöntemini geliştirmek için kullanılan verilere ilaveten sıcaklık ve yağış gibi iklim, temel toprak suyu ile ölçülmüş ET verileri edinilmiştir. Her bir ölçüm periyodu için güneş radyasyonu $\left(R_{s}\right)$, özellikle bir veya birden fazla bulutla kaplı istasyonun olduğu veri setlerinden tahmin edilmiştir. Bunun da yaklaşık 1000 ölçülmüş ET verisine karşılık geldiği ifade edilmiştir. Tamamen bitki ile kaplı alanlardan ölçülen verilere yoğunlaşıldığında yaklaşık 100 veri seti çalışmada kullanılabilir bulunmuştur. PET ile $\mathrm{R}_{\mathrm{s}}$ arasında 1962 yılında önerilen bağıntı:

$\lambda \mathrm{ET}=(0.014 \mathrm{~T}-0.37) \mathrm{R}_{\mathrm{s}}$

şeklindedir ve $\lambda$ buharlaşma gizli ssısı $\left(\mathrm{MJkg}^{-1}\right)$, T ortalama sıcaklıktır $\left({ }^{\circ} \mathrm{F}\right)$. $\mathrm{R}_{\mathrm{s}}{ }^{\prime}$ in birimi mm (veya inç)/gün. Literatürde verilen ve bu çalışmada kullanılan bir diğer JH formülü ise aşağıdaki gibidir:

$\lambda E T=(0.025 \mathrm{~T}+0.08) \mathrm{R}_{\mathrm{s}}$

ortalama sıcaklığın birimi ${ }^{\circ} \mathrm{C}$. Çalışma buharlaşma için gerekli birincil enerjinin sıcaklık yerine güneş enerjisi olduğunu vurgulaması açısından, önerildiği zaman için önemlidir [33].

\section{FAO-56 Penman-Monteith (FAO-56 PM)}

Bir yüzeyden suyun evapotranspirasyon olarak uzaklaşabilmesi için gerekli mekanizmalar enerji kaynağı ve buhar taşınımıdır. Enerji kaynağı suyun sıvı halden buhar haline geçmesini sağlayacak buharlaşma gizli ısısı için gereklidir. Buhar taşınım mekanizması ise ortamdaki su buharının yüzeyden uzaklaştırılarak, buharlaşma yüzeyi ve çevreleyen hava arasındaki buhar basıncı değişimini sağlamak için gereklidir. 1950'li yıllara kadar ET tahmini için geliştirilen yöntemler bunlardan sadece birini dikkate alıyorlardı. Enerji dengesine ve kütle transferine (aerodinamik) dayalı yöntemler olarak biliniyorlardı. Penman bu iki yaklaşımı bir arada düşünmüş ilk kişi olup, sadece meteorolojik değişkenlere dayalı olarak ampirik rüzgâr fonksiyonu içeren açık su yüzeyinden buharlaşma tahmini için önerdiği yöntem kombinasyon yöntemi olarak tanımlanmaktadır [34]. Penman ayrıca önerdiği yöntemin kısayeşil-çim kaplı alanlardan ET tahmini için kullanılabileceğini ifade etmiştir. Bunun için serbest yüzey buharlaşma tahmini ile yılın zamanına bağlı olarak 0.6'dan 0.8'e değişen ampirik katsayının çarpılması gerektiğini vurgulamıştır. Penman daha sonra stoma geometrisini yansıtan stoma faktörünü ve stomanın kapanmasına neden olan gün uzunluğu faktörünü hesaba katan yeni bir denklemi 1952'de önermiştir. Geliştirdiği denklemin herhangi kısa-yeşil bitki örtüsü için kullanılabileceğini, uzun bitki örtüsü için uyarlanmış rüzgâr fonksiyonunun kullanılmasını tavsiye etmiştir. 1963 çalışmasında orijinal denklemine geri dönerek, kısa-yeşil-iyi sulanmış çim referans bitkisinden ET’nin direk hesaplanmasına olanak sağlayan ampirik rüzgâr fonksiyonunun yeni bir kalibrasyonunu önermiştir [34].

Monteith, Penman denkleminin yeni versiyonunu elektriksel anolog temelli türetmiştir. Denklemi tamamen fiziksel temelli olup iki direnç terimi içermektedir. Aerodinamik direnç ampirik rüzgâr fonksiyonu yerini alırken, yüzey direnci Penman'ın stoma ve gün uzunluğu faktörü yerini almıştır [34]. Allen ve ark. yaptıkları çalışmada, Penman-Monteith (PM) 
denklemini 0.23 albedo ve $70 \mathrm{~s} / \mathrm{m}$ sabit yüzey direncine sahip $12 \mathrm{~cm}$ yüksekliğinde olduğu varsayılan referans bitkiye göre uyarlamışlardır. Yeşil çim yüzeyinin tekdüze yükseklikte, büyüme evresinde ve yeterli suya sahip olduğu varsayılmıştır. FAO-56 PM referans (potansiyel) ET denklemi, PM denklemi, aerodinamik ve yüzey direnci denklemleri kullanılarak elde edilmiştir [5]:

$\mathrm{PET}=\frac{0.408 \Delta\left(R_{n}-G\right)+\left(\gamma \frac{900}{T+273}\right) u_{2}\left(e_{s}-e_{a}\right)}{\Delta+\gamma\left(1+0.34 u_{2}\right)}$

eşitlikteki $R_{n}$ net güneş radyasyonu $\left(\mathrm{MJm}^{-2} \mathrm{gün}^{-1}\right)$; $\mathrm{G}$ toprak 1S1 akısı $\left(\mathrm{MJm}^{-2} \mathrm{gün}^{-1}\right)$; $\mathrm{e}_{\mathrm{s}}$ buharlaşma yüzeyindeki ve $\mathrm{e}_{\mathrm{a}}$ havadaki buhar basıncı; $\mathrm{u}_{2} 2 \mathrm{~m}$ yükseklikte ölçülmüş rüzgar hızı $(\mathrm{m} / \mathrm{s}) ; \gamma$ psikrometrik sabiti $\left(\mathrm{kPa}^{\circ} \mathrm{C}^{-1}\right) ; \Delta$ doygun buhar basıncı sıcaklık eğrisinin eğimidir $\left(\mathrm{kPa}^{\circ} \mathrm{C}^{-1}\right)$. Kullanılacak meteorolojik verilerin su sıkıntısı çekmeyen, toprağı kaplamış yeşilçim yüzeyin $2 \mathrm{~m}$ üzerinden ölçülmüş olması gerekmektedir [5].

\section{Makkink (MK)}

Hollanda'nın soğuk ve nemli iklim koşullarında çim kaplı yüzeylerden gerçekleşen ET'yi iklim verileri ve güneş radyasyonundan ampirik olarak hesaplamak için Makkink tarafından önerilmiştir [35]:

$\mathrm{PET}=0.61 \frac{\Delta}{\Delta+\gamma} \frac{R_{S}}{\lambda}-0.12$

Yöntem sadece güneş radyasyonu ve sicaklık verisi gerektirmektedir. $\Delta$ sicaklıktan türetilirken, $\gamma$ (psikrometrik) sabitine söz konusu bölgenin yükseklik ve enlemine göre karar verilmektedir.

\section{Turc (TC)}

Turc evapotranspirasyon miktarının güneş radyasyonu, sıcaklık ve nispi nem değişkenleri ile ampirik olarak hesaplanabilmesi için Batı Avrupa nemli iklim koşulları altındaki verilerini kullanarak ampirik bir denklem geliştirmiştir [36]:

$\mathrm{PET}=0.013 \mathrm{C} \frac{T}{T+15}\left(\mathrm{R}_{\mathrm{s}}+50\right)$

C parametresi nispi nem (RH) ile ilişkilendirilmiş olup nispi nem \%50'den büyük ise bir (1), küçük ise $1+\left(50-\mathrm{RH}_{\text {ort }}\right) / 70$ olarak tanımlanmıştır. Yöntemin ortalama sıcaklığın $10^{\circ} \mathrm{C}$ 'den küçük olduğu durumlarda kullanılmaması önerilmiştir. C parametresi için önerilen formülasyon fiziksel olarak yorumlandığında, nispi nem \%50 kesme seviyesinin altına düştükçe verilen sıcaklık ve radyasyonda ET'nin lineer olarak artacağı anlaşılmaktadır. Buradan C katsayısının Penman-Monteith denkleminde tanımlanan buhar eksikliği terimi ile ilişkilendirilmeye çalışıldığı anlaşılmaktadır. Yüksek nispi nemli ortamlarda nispi nemin ET üzerinde etkisi olmadığı varsayılmıştır. 


\section{Priestley-Taylor (PT)}

Priestley ve Taylor, tamamen suya doygun yüzeylerde buharlaşma gizli 1sısı (LE) ile hissedilir 1sı (H) arasında aşağıdaki eşitliği önermişlerdir [9]:

$\frac{L E}{L E+H}=\alpha\left(\frac{\Delta}{\Delta+\gamma}\right)$

$\alpha$ katsayısının suya doygun olmayan yüzeylerde de kullanılabileceğini, bu durumda suya doygun yüzeylerdekinden daha küçük bir değer almasının beklenmesi gerektiğini, Dodds ve ark., ise onların aksine daha az nemli ortamlarda $\alpha$ katsayısının artırılarak kullanılması gerektiğini ifade etmişlerdir [37]. Aslında Priestley ve Taylor, Penman'ın doygun toprak yüzeyinden buharlaşma oranını bulmak için 1948 yılında önerdiği formüldeki:

$L E=\frac{\Delta}{\Delta+\gamma}\left(R_{n}-G\right)+\frac{\gamma}{\Delta+\gamma} h\left(e_{s}-e_{a}\right)$

enerji (birinci) bileşenin aerodinamik (ikinci) bileşeninine baskın olduğu durumlar için yeni bir buharlaşma tahmin formülü geliştirmişlerdir. $\mathrm{Bu}$ durumda $\mathrm{LE}+\mathrm{H}=\mathrm{R}_{\mathrm{n}}-\mathrm{G}$. Adveksiyon (yatay hava hareketi) oluşmaması durumunda bu denklemin olası günlük ortalama buharlaşma oranı üzerinde sınırlar konulabilmesini sağladığını iddia etmişlerdir. İlk sınır koşul, $H$ negatif bir değer alamayacağı için $L E<R_{n}-G$ ise $\alpha<(1+\gamma / \Delta)$ olmak durumundadır. İkinci sınır koşul, aerodinamik bileşendeki doygunluk açığının $\left(\mathrm{e}_{\mathrm{s}^{-}} \mathrm{e}_{\mathrm{a}}\right)$ negatif olması ve dolayısıyla yoğunlaşma olma olasılığı düşük olduğundan yoğunlaşma oluşmaması gerekliliğidir. Bu durumda, $L E>\frac{\Delta}{\Delta+\gamma}\left(R_{n}-G\right)$ olması gerektiğinden $\alpha>1$ olmalıdır. $\Delta /(\Delta+\gamma)$ teriminin $10^{\circ} \mathrm{C}$ yüzey sıcaklığında $0.56^{\prime}$ dan $35^{\circ} \mathrm{C}$ de $0.82^{\prime}$ ye değiştiğini ve belirttikleri iki koşulun adveksiyon etkinin bulunmaması için minimum kriter olarak alınabileceğini ifade etmişlerdir. Sonuç olarak bu yöntemde adveksiyon değerlerinin oldukça küçük olduğu varsayımı yapılarak, Penman metodunun kütle transferi bileşenlerinin etkisi bir katsayıya $(\alpha)$ indirgenmiştir [17]. Literatürde paylaşılan suya doygun karasal alanlanlardan ve açık su yüzeylerinde gözlemlenen veriler kullanılarak $\alpha$ değeri tahmin edilmeye çalışılmıştır. Kullanılan gözlemlerden en iyi tahminin (kara ve su) 1.26 olduğu belirtilmiştir [9]. Morton, karasal alanlarda $\alpha=1.26$ katsayısı kullanıldığında ET'nin düşük tahmin edildiğini ileri sürmüş ve buna sebep olarak karasal alanların açık yüzeylere göre daha heterojen ve engebeli olmasını göstermiştir. Karasal alanlar için $\alpha$ katsayısının 1.32 olarak alınmasının daha uygun olacağını belirtmiştir [37, 38]. $\alpha$ katsayısı üzerine çalışmalara devam edilmesine karşın, yöntem geniş ormanlık alanlar ve nemli ortamlar için daha uygun olmakla birlikte az veriye ihtiyaç duyması sebebiyle önerilen şekliyle kullanılmaya devam etmektedir. Yöntemin enerjinin yatay olarak taşınımını ifade eden adveksiyonun etkin olduğu durumlarda daha az evapotranspirasyon değeri tahmin edebildiği unutulmamalıdır [32].

\section{Hargreaves-Samani (HS)}

Hargreaves, 8-15 cm arasında yüksekliğe sahip kırpılmış otlak alandan iki bin dokuz yüz bir (2 901) W.O. Pruitt (yayımlanmamış) tarafından Kaliforniya Davis'de alta fescue referans bitkisi için kurulan tartılabilir lizimetre düzeneğinden ölçülen evapotranspirasyon $\left(\mathrm{ET}_{\mathrm{g}}\right)$ 
değerleri ile ortalama sıcaklık (Fahrenhayt) ve yüzeyde ölçülen global güneş radyasyon $\left(\mathrm{R}_{\mathrm{s}}\right)$ çarpımı arasında lineer bir ilişki elde etmeye çalışmıştır. Elde ettiği lineer denklemin $\mathrm{ET}_{\mathrm{g}}$ değerlerinin \%94'ünü açıkladığını saptamıştır [39]:

$\mathrm{PET}=0.0075 \mathrm{R}_{\mathrm{s}} \mathrm{TF}$

Sıcaklık birimi olarak derece kullanıldığında denklem;

$\mathrm{PET}=0.0135 \mathrm{R}_{\mathrm{s}}(\mathrm{TC}+17.8)$

halini almaktadır. Rüzgâr hızının $\left(\mathrm{u}_{2}\right)$ ve bağıl nemin $(\mathrm{RH})$ ET'ye olan fiziksel etkilerini ortaya koymak için ET/ET $\mathrm{E}_{\mathrm{g}}$ oranı ile sırasıyla $\mathrm{u}_{2}$ ve $\mathrm{RH}$ arasında ilişki aranmıştır. Rüzgârın söz konusu oranın \%10'unu, RH'in \%9'unu açıkladığı saptandığından, bu iki değişken veri gerekliliğini azaltmak ve denklemin basitliğini bozmamak adına dahil edilmemiştir. 1977 yılındaki çalışmasında elindeki gözlem verilerinin analizinden ve literatürde araştırmacıların karşılaştı̆̆ 1 zorluklardan $R_{s}$ 'in mümkün güneşlenme $(S)$ yüzdesi ve uzay radyasyonundan $\left(R_{a}\right)$ hesaplanabileceği sonucuna varmış ve aşağıdaki denklemi önermiştir [40]:

$\mathrm{R}_{\mathrm{s}}=0.075 \mathrm{R}_{\mathrm{a}} \mathrm{S}^{0.50}$

S, güneşlenme saatinin yüz ile çarpılıp mümkün güneşlenme saatleri sayısına bölünmesiyle ölçülen değişkendir. Hargreaves ve Samani çalışmalarında $R_{s}$ 'in hesaplamasını sıcaklık değişkenine bağlamıştır [41]:

$\mathrm{R}_{\mathrm{s}}=\mathrm{K}_{\mathrm{RS}} \mathrm{R}_{\mathrm{a}} \mathrm{TR}^{0.50}$

eşitlikteki TR ortalama günlük maksimum ve minimum sıcaklık farkı; $\mathrm{K}_{\mathrm{RS}}$ ampirik katsayıdır. Hargreaves, Senegal nehir havzasından aldığ 0.16 olarak bulmuştur ve denklem 10 ve 12 'den $\mathrm{K}_{\mathrm{RS}}=0.16$ alınarak, aşağıdaki denklemi elde etmiştir [42]:

$\mathrm{PET}=0.0022 \mathrm{R}_{\mathrm{a}}(\mathrm{TC}+17.8) \mathrm{TR}^{0.50}$

Hargreaves ve Samani, pik taleplerin olduğu aylar için katsayının 0.0023 'e yükseltilmesini önermişlerdir. Bu uyarlama ile elde edilen denklem 1985 Hargreaves-Samani denklemi olarak bilinmektedir [43]:

$\mathrm{PET}=0.0023 \mathrm{R}_{\mathrm{a}}(\mathrm{TC}+17.8) \mathrm{TR}^{0.50}$

Yöntem basit, minimum veri gereksinimi olması ve kolay hesaplanabilmesi bakımından tercih edilmektedir. Özellikle sadece sıcaklık verisinin bulunduğu bölgelerde yaygın olarak kullanılmaktadır. Allen çalışmasında Hargreaves-Samani denklemini geliştirmeyi amaçlayarak aşağıdaki eşitliği önermiştir:

PET $=0.0029 \mathrm{R}_{\mathrm{a}}(\mathrm{TC}+20) \mathrm{TR}^{0.40}$ 
1964-1972 günlük Davis veri setini kullandığında önerdiği denklem için $r^{2}=0.96$ ve hata miktarını 0.93 mmgün $^{-1}$ bulurken, orijinal denklem için bu değerlerin sırasıyla 0.95 ve 0.98 mmgün $^{-1}$ olduğunu tespit etmiştir. Elde edilen iyileşmenin önemli olmadığı kanısına varılarak orijinal denklemin kullanılabileceği ifade edilmiştir [44].

\section{BULGULAR VE TARTIŞMA}

Konya Kapalı Havzasından seçilen beş istasyondan alınan Mart-Kasım dönemlerine ait günlük meteorolojik veriler ile istasyon bazlı PET tahminleri ampirik yöntemler ile yapılmıştır. Çalışmada kullanılan meteorolojik değişkenlerin uzun yıllar günlük ortalama değerleri Çizelge 2'de sunulmuştur.

\section{Çizelge 2 - Çalışma dönemi (Mart-Kasım) için meteorolojik değişkenlerin uzun yıllar günlük ortalama değerleri}

\begin{tabular}{cccccccc}
$\begin{array}{c}\text { İstasyon } \\
\text { Adı }\end{array}$ & $\begin{array}{c}\boldsymbol{T}_{\boldsymbol{m a k}} \\
\left({ }^{\circ} \mathrm{C}\right)\end{array}$ & $\begin{array}{c}\boldsymbol{T}_{\boldsymbol{m i n}} \\
\left({ }^{\circ} \mathrm{C}\right)\end{array}$ & $\begin{array}{c}\boldsymbol{T}_{\text {ort }} \\
\left({ }^{\circ} \mathrm{C}\right)\end{array}$ & $\begin{array}{c}\boldsymbol{R H} \\
(\%)\end{array}$ & $\begin{array}{c}\boldsymbol{u}_{\mathbf{2}} \\
(\boldsymbol{m} /\end{array}$ & $\begin{array}{c}\boldsymbol{R}_{\boldsymbol{s}} \\
(\mathbf{c a l} /\end{array}$ & $\begin{array}{c}\mathbf{P} \\
(\boldsymbol{m m})\end{array}$ \\
\hline Aksaray & 30,0 & 3,9 & 16,6 & 50,2 & 2,5 & 14376 & 232,6 \\
Ereğli & 30,7 & 3,0 & 16,5 & 55,4 & 1,9 & 14796 & 211,7 \\
Karaman & 30,2 & 2,4 & 15,9 & 53,7 & 2,2 & 14202 & 201,9 \\
Karapınar & 30,7 & 0,5 & 15,3 & 56,7 & 2,2 & 14882 & 196,2 \\
Niğgde & 28,6 & 3,5 & 15,5 & 52,5 & 2,5 & 15910 & 241,5
\end{tabular}

FAO-56 PM yönteminden elde edilen tahminler referans olarak kullanılarak, Blaney-Criddle, Jensen-Haise, Makkink, Turc, Priestley-Taylor ve Hargreaves-Samani ampirik yöntemlerinin bölge için PET tahmin performansları değerlendirilmiştir. Değerlendirme ortalama hata kareleri karekökü (RMSE) ve belirleme katsayısı $\left(\mathrm{R}^{2}\right)$ ile yapılmış ve Çizelge 3 'te sunulmuştur. Belirleme katsayısı $\left(\mathrm{R}^{2}\right)$ değişkenler arasındaki ilişkiyi en iyi ifade eden lineer çizgiye yakın olan verilerin yüzdesini belirlemek için kullanılmıştır. Aksaray ve Ereğli istasyonları için görsel olarak kıyaslama Şekil 1'de sunulmuştur.

FAO-56 PM ile ampirik yöntemler arasındaki ilişkinin incelenmesinden, MK yöntemi tahminlerinin genel olarak daha düşük kaldığı tespit edilmiştir. Ancak, Aksaray istasyonu haricindeki diğer istasyonlar için yapılan tahminlerin 2 mm'ye kadar FAO-56 PM tahminleri ile uyumlu olduğu saptanmıştır. Iran'da dört farklı iklim etkisi altındaki istasyonlarda yapılan çalışmada da soğuk nemli iklim bölgesi haricindeki istasyonlarda MK yönteminin FAO-56 PM’e kıyasla düşük tahminlerde bulunduğu tespit edilmiştir [17].

JH ampirik yöntemi genel olarak 4 mm'nin üzerindeki tahminlerde daha yüksek kalırken, 4 mm altındaki tahminlerde daha düşük kalmıştır. Nemli iklim koşulları için geliştirilen bir yöntem olması gözönünde tutulduğunda, yüksek tahminlerin elde edilmesi şaşırtıcı değildir. $\mathrm{BC}$ yöntemi genel olarak FAO-56 PM tahminlerinden daha yüksek tahminlerde bulunmuştur. Aksaray, Karapınar ve Niğde istasyonlarında $5.5 \mathrm{~mm}$ 'nin üzerinde ise daha düşük tahminlere 
rastlanmıştır. Yöntemin, Burkino Faso-Afrika gibi kuru tropik iklim [45], Kaliforniya-ABD ve Iran gibi çorak iklim [46, 47], İspanya gibi yarı çorak iklim [11] bölgelerinde de yüksek tahminler verdiği rapor edilmiştir. TC yöntemi $4 \mathrm{~mm}$ 'ye kadar genel olarak daha düşük tahminler vermiştir. 4 mm'den daha yüksek değerlerdeki tahminleri Aksaray, Karaman ve Karapınar istasyonlarında FAO-56 PM tahminlerine oldukça yakınken, diğer istasyonlarda tahminler yüksek kalmıştır. 4 mm'ye kadar olan ET tahminleri karşıllaştırılan yöntem ile en yakın olan HS yöntemidir. Aksaray ve Niğde istasyonları için yaptı̆̆ tahminler genel olarak başarılıyken, diğer istasyonlarda $4 \mathrm{~mm}$ üzerinde yüksek tahminler elde edildiği saptanmıştır. Yapılan çalışmalar HS yönteminin ılıman, nemli ve yarı çorak iklimlerde yüksek tahminler verdiğini ortaya koymasına rağmen, yarı çorak iklim etkisi altındaki rüzgarlı bölgelerde iyi sonuçlar verdiğini yadsımamışlardır [16]. Bu bilgi yarı çorak iklim etkisi altında, diğer istasyonlara nazaran rüzgarlı sayılabilecek Aksaray ve Niğde istasyonlarından elde edilen sonuçlar ile tutarlıdır. PT yönteminin tüm istasyonlarda $4 \mathrm{~mm}$ 'ye kadar daha düşük tahmin yapma eğilimde olduğu saptanmıştır. Yöntem Aksaray haricindeki istasyonlarda genel olarak oldukça yakın sonuçlar verirken, söz konusu istasyondaki tahminler FAO-56 PM yönteminden daha düşük kalmıştır.

Hesaplanan RMSE değerleri gözönüne alındığında Ereğli, Karaman ve Karapınar istasyonları için FAO-56 PM yöntemine en yakın tahminler PT ampirik yönteminden; Aksaray ve Niğde istasyonları için en yakın tahminler ise HS ampirik yöntemi ile elde edilmiştir. Aksaray ve Ereğli istasyonları için ampirik yöntemlerin uzun yıllar günlük ortalama PET tahminlerinin aylık ortalama değer kıyaslamaları Şekil 2'de sunulmuştur.
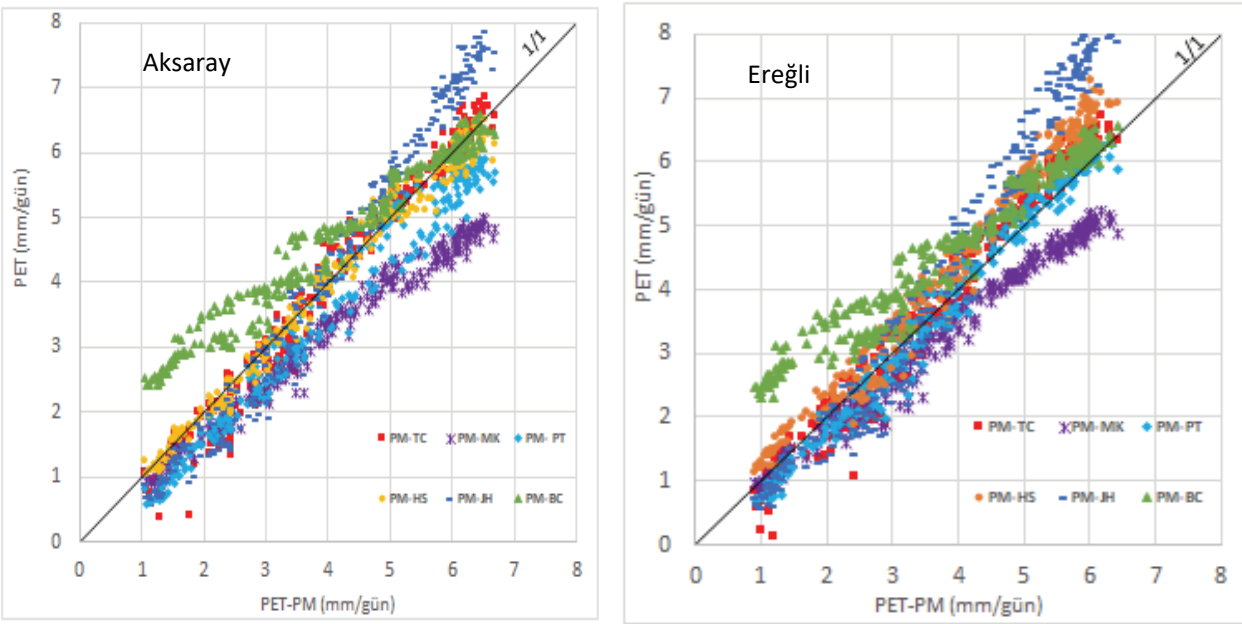

Şekil 1 - Aksaray ve Ereğli istasyonları için ampirik yöntemlerin FAO-56 PM ile klyaslaması 
Çizelge 3 - Ampirik yöntemlerin FAO56-PM ile klyaslanması

\begin{tabular}{|c|c|c|c|c|c|c|}
\hline \multicolumn{2}{|c|}{$\begin{array}{l}\text { İstasyon adı/ } \\
\text { Yöntem }\end{array}$} & \multirow{2}{*}{$\begin{array}{c}\text { Aksaray } \\
0,34\end{array}$} & \multirow{2}{*}{$\begin{array}{c}\text { Ereğli } \\
037\end{array}$} & \multirow{2}{*}{$\begin{array}{c}\text { Karaman } \\
0,37\end{array}$} & \multirow{2}{*}{$\begin{array}{c}\text { Karapınar } \\
0,36\end{array}$} & \multirow{2}{*}{$\begin{array}{c}\text { Niğde } \\
0,43\end{array}$} \\
\hline $\mathrm{TC}$ & RMSE & & & & & \\
\hline & $\mathrm{R}^{2}$ & 0,98 & 0,98 & 0,97 & 0,97 & 0,98 \\
\hline \multirow[t]{2}{*}{ MK } & RMSE & 1,07 & 0,64 & 0,82 & 0,71 & 0,70 \\
\hline & $\mathrm{R}^{2}$ & 0,98 & 0,98 & 0,98 & 0,98 & 0,99 \\
\hline \multirow[t]{2}{*}{ PT } & RMSE & 0,64 & $0,27 *$ & $0,33^{*}$ & $0,26^{*}$ & 0,34 \\
\hline & $\mathrm{R}^{2}$ & 0,96 & $0,98^{*}$ & $0,98^{*}$ & $0,98^{*}$ & 0,98 \\
\hline \multirow[t]{2}{*}{ HS } & RMSE & $0,27^{*}$ & 0,55 & 0,44 & 0,58 & $0,29 *$ \\
\hline & $\mathrm{R}^{2}$ & $0,98^{*}$ & 0,98 & 0,98 & 0,98 & $0,99 *$ \\
\hline \multirow[t]{2}{*}{$\mathrm{JH}$} & RMSE & 0,62 & 1,03 & 0,75 & 0,81 & 0,91 \\
\hline & $\mathrm{R}^{2}$ & 0,98 & 0,96 & 0,97 & 0,97 & 0,97 \\
\hline \multirow[t]{2}{*}{$\mathrm{BC}$} & RMSE & 0,73 & 0,87 & 0,82 & 0,79 & 0,66 \\
\hline & $\mathrm{R}^{2}$ & 0,97 & 0,96 & 0,96 & 0,96 & 0,97 \\
\hline
\end{tabular}

Not: * işareti RMSE için en küçük değeri, $\mathrm{R}^{2}$ için en yüksek değeri göstermektedir.
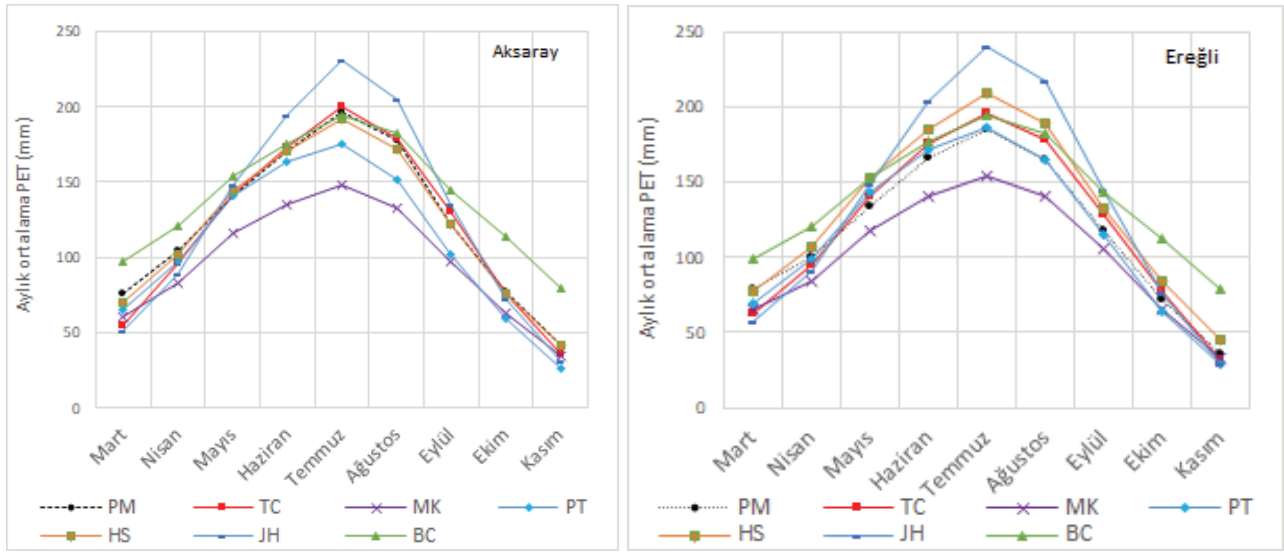

Şekil 2 - Aksaray ve Ereğli istasyonları aylık ortalama bazında ampirik yöntem tahminlerinin klyaslanması

Aylık ortalama PET bazında bakıldığında tüm istasyonlar için MK yöntemi ile FAO-56 PM yöntemine göre daha düşük tahminler yapılırken, $\mathrm{BC}$ yöntemi ile daha yüksek tahminlerde bulunulmuştur. JH yöntemi ise Mayıs-Eylül aylarında yüksek, diğer aylarda ise düşük tahminler vermiştir. TC, PT ve HS yöntemlerinden elde edilen tahminler gözönüne alındığında FAO-56 PM yöntemine alternatif olabilecekleri tespit edilmiştir. Aksaray 
istasyonu için Haziran-Kasım ayları tahmin değerleri dikkate alındığında en yakın tahminler TC yönteminden, Mart-Haziran ve Eylül-Kasım ayları tahmin değerleri dikkate alındığında ise en yakın tahminler HS yönteminden elde edilmiştir. PT yöntemi tahminleri bu istasyon için düşük kalmıştır. Ereğli istasyonunda Mayıs-Kasım ayları için TC ve HS yöntemlerinden yüksek tahminler elde edilmiş, en iyi tahminlere PT yöntemi ile ulaşılmıştır. Karaman istasyonunda Mayıs-Kasım ayları için FAO-56 PM yöntemine yakın tahminlerde bulunan TC yöntemidir. HS yöntemi tahminleri yüksek, PT tahminleri düşük kalmıştır. Karapınar istasyonu için en iyi tahmin PT yönteminden elde edilirken, TC sadece Mart-Nisan aylarında düşük tahminde bulunmuştur. HS ise neredeyse tüm aylarda FAO-56 PM tahminlerinin üzerinde kalmıştır. Niğde istasyonunda en iyi tahminler Temmuz ayına kadar PT, Temmuz ayından sonra HS yönteminden elde edilmiştir. TC yöntemi Haziran-Ağustos aylarında yüksek, Mart-Nisan aylarında düşük tahminlerde bulunmuştur.

Sulama sezonunun Mayıs-Ekim ayları arası olduğu düşünülürse TC yönteminin Aksaray, Karaman ve Karapınar istasyonları için, PT yönteminin ise Ereğli ve Niğde istasyonları için önerilebileceği sonucuna varılmıştır. PT yöntemi Niğde istasyonunda Aksaray, Karaman ve Karapınar istasyonlarında olduğu gibi daha düşük tahminlerde bulunmasına rağmen, FAO56 PM yöntemi tahminlerine TC'den daha yakın sonuçlar verdiği için önerilmiştir. Sonuçlar yorumlandığında bölge için FAO-56 PM'e alternatif evapotranspirasyonu yöntemi olarak PT önerilecekse, bölgedeki diğer meteorolojik istasyon verileri edinilerek bölgesel $\alpha$ katsayısının bulunması gerektiği sonucuna varılmıştır. Literatürde yöntemin karasal alanlarda orijinal hali ile kullanılması durumunda düşük tahminler elde edileceği bulgusu çalışılan bölge için de geçerli olmuştur.

\section{SONUÇLAR}

Bu çalışmada, dünyanın birçok bölgesinde yaygın bir şekilde kullanılan ve güvenilir PET tahminleri yaptığı iddia edilen ampirik yöntemler tanıtılarak, Konya Kapalı Havzası özelinde kullanılarak sonuçları irdelenmiştir. İstatistiksel olarak bakıldığında FAO-56 PM'ye en yakın tahminlerin elde edildiği ikinci yöntem istasyon bazında değişse dahi TC yöntemidir (Niğde istasyonu haricinde). HS yöntemi Aksaray ve Niğde istasyonları için birinci, Ereğli, Karaman ve Karapınar istasyonları için üçüncü sırada yer almıştır. PT yöntemi ise Ereğli, Karaman ve Karapınar istasyonları için birinci, Niğde istasyonu için ikinci sırada yer almıştır.

Sonuç olarak Konya Kapalı Havzasında çalışmaya dahil edilen istasyonlar için yapılan incelemede, günlük PET tahminlerinde elde yeteri kadar ölçülmüş günlük meteorolojik gözlem verisinin bulunmaması durumunda TC, HS ve PT yöntemleri FAO-56 PM'e alternatif olarak ön plana çıkmıştır. Mayıs-Kasım ayları dikkate alındığında PET tahminleri için önerilen TC yöntemidir. Bölgedeki üç istasyonda FAO-56 PM ile en yakın tahminleri yapan birinci yöntem olarak PT bulunmasına rağmen, yöntemden genellikle düşük tahminler elde edildiğinden $\alpha$ katsayısının artırılması gerektiği sonucuna varılmıştır. Ayrıca, sadece günlük sıcaklık verisine ihtiyaç duyan HS yönteminin bölge özelindeki performansının yadsınamayacak derecede başarılı olduğu belirtilmeden geçilemez. MK, BC ve JH yöntemlerinin bölge bazında başarılı olmadığı tespit edilmiştir. Havzayı temsil etmekte beş istasyonun yeterli olamayabileceği akılda tutularak, çalışmanın önemli tarımsal faaliyetlere ev sahipliği yapan havzada yapılacak tarımsal sulama planlamaları, su bütçesi, yağış-akış 
modelleri, kuraklık ve iklim değişikliği çalışmalarında seçilecek PET tahmin yöntemini belirlemede yararlı olacağı inancı taşınmaktadır.

\section{Semboller}

$\alpha \quad$ : Priestley-Taylor katsayıs1,

$\Delta \quad$ : Doygun buhar basıncı sıcaklık eğrisinin eğimi,

$\lambda \quad$ : Buharlaşma gizli ısı katsayısı,

$\gamma \quad$ : Psikrometrik sabit,

BC : Blaney Criddle,

C : Sabit katsay1,

E : Buhar basinc1,

ET : Evapotranspirasyon,

f : İklim parametresi,

FAO : Gida ve Tarım Organizasyonu,

G : Toprak 1sı akıs1,

$\mathrm{H} \quad$ : Hissedilir 1s1,

HS : Hargreaves-Samani,

JH : Jensen Haise,

$\mathrm{k} \quad$ : Bitki su tüketim katsayısı,

$\mathrm{K}_{\mathrm{RS}} \quad$ : Ampirik katsay,

LE : Buharlaşma gizli 1sısı,

MK : Makkink,

$\mathrm{p} \quad$ : Gündüz saatlerinin aylık yüzdesi,

PET : Potansiyel Evapotranspirasyon,

PM : Penman-Monteith,

PT : Priestley-Taylor,

$\mathrm{R}_{\mathrm{a}}$ : Uzay radyasyonu,

$\mathrm{R}_{\mathrm{n}} \quad$ : Net güneş radyasyonu,

$\mathrm{R}_{\mathrm{s}} \quad$ : Güneş radyasyonu,

$\mathrm{R}^{2} \quad$ : Belirleme katsayısı, 


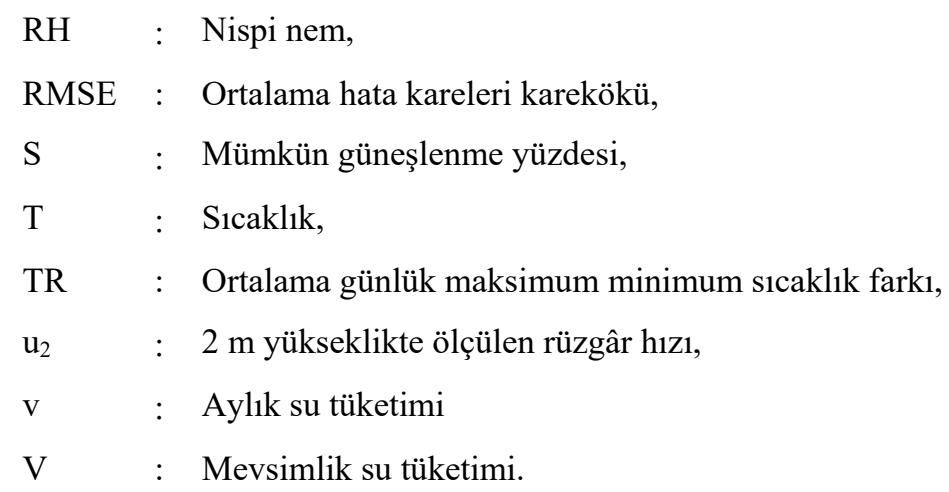

\section{Kaynaklar}

[1] Katul, G.G., Oren, R., Manzoni, S., Higgins, C., Parlange, M.B., Evapotranspiration: A process Driving Mass Transport and Energy Exchange in the Soil-Plant-AtmosphereClimate System. Rev. Geophys., 50, RG3002, 2012.

[2] Dingman, S.L., Physical Hydrology, Long Grove, Waveland Press, Inc., 2008.

[3] Akpolat, A., Mikrometeorolojik ve Lizimetre Yöntemleriyle Belirlenen Buğday Bitki Su Tüketimlerinin Karşılaştırılması. Master Tezi, Çukurova Üniversitesi, Adana, 2011.

[4] Abdulkareem, J.H., Abdulkadir, A., Abdu, N., A Review of Different Types of Lysimeter Used in Solute Transport Studies. International Journal of Plant \& Soil Science 8(3), 1-14, 2015.

[5] Allen, R.G, Periera, L.S, Raes, D., Smith, M., Crop Evapotranspiration-Guidelines for Computing Crop Water Requirements - FAO Irrigation and Drainage Paper 56. Food and Agriculture Organization of the UN, Rome, Italy, 1998.

[6] Lingling, Z., Jun, X., Chong-yu, X., Zhonggen, W., Leszek, S., Cangrui, L., Evapotranspiration Estimation Methods in Hydrological Models, J. Geogr. Sci., 23(2), 359-369, 2013.

[7] Alexandris, S., Stricevic, R., Petkovic, S., Comparative Analysis of Reference Evapotranspiration from the Surface of Rainfed Grass in central Serbia, Calculated by Six Empirical Methods against the Penman-Monteith Formula. European Water, 21/22, 17-28, 2008.

[8] Monteith, J.L., Evaporation and the Environment. XIX th Symposium Society for Experimental Biology, Swansea, Cambridge University, Cambridge, England, 205234, 1965.

[9] Priestley, C.H.B, Taylor, R.J., On the Assessment of the Surface Heat Flux and Evaporation using Large-Scale Parameters. Monthly Weather Review, 100, 81-92, 1972.

[10] Lemeur, R., Zhang, L., Evaluation of Three Evapotranspiration Models in terms of their Applicability for an Arid Region. Journal of Hydrology, 114 (3-4), 395-411,1990. 
[11] Lopez-Urrea, R., De Santo Olalla, F. M., Fabeiro, C., Moratalla, A., An Evaluation of Two Hourly Reference Evapotranspiration Equations for Semi-arid Conditions. Agricultural Water Management, 86(3), 277-282, 2006.

[12] Sentelhas, P.C., Gillespie, T.J., Santos, E.A., Evaluation of FAO Penman-Monteith and Alternative Methods for Estimating Reference Evapotranspiration with Missing Data in Southern Ontario, Canada. Agricultural Water Management, 97, 635-644, 2010.

[13] Salih, A.M.A., Sendil, U., Evapotranspiration Under Extremely Arid Environment. J Irrig Drain Eng., 110(3), 289-303, 1983.

[14] Beyazgül, M., Kayam, Y., Engelsman, F., Estimation Methods for Crop Water Requirements in the Gediz Basin of Western Turkey. Journal of Hydrology, 229, 1926, 2000.

[15] Şahin, Ü., Angın, İ., Anapalı, Ö., Evaluation of Reference Evapotranspiration Calculation Methods Applied to the Climatic Conditions of Turkey. J Hydrol. Hydromech., 52 (2), 125-133, 2004.

[16] Lu, J., Sun, G., McNulty, S.G., Amatya, D.M., A Comparison of Six Potential Evapotranspiration Methods for Regional use in the Southeastern United States. JAWRA, 41(3), 621-633, 2005.

[17] Tabari, H., Evaluation of Reference Crop Evapotranspiration Equations in Various Climates. Water Resour. Manag., 24, 2311-2337, 2010.

[18] Tukimat, N.N.A., Harun, S., Shahid, S., Comparison of Different Methods in Estimating Potential Evapotranspiration at Muda Irrigation Scheme of Malaysia. Journal of Agriculture and Rural Development in the Tropics and Subtropics, 113 (1), 77-85, 2012.

[19] Fisher, D.K., Pringle III, H.C., Evaluation of Alternative Methods for Estimating Reference Evapotranspiration. Agricultural Sciences, 4(8A), 51-60, 2013.

[20] Efthimiou, N., Alexandris, S., Karavitis, C., Mamassis, N., Comparative Analysis of Reference Evapotranspiration Estimation between Various Methods and the FAO56 Penman-Monteith Procedure. European Water, 42, 19-34, 2013.

[21] Uçar, Y., Kazaz, S., İnal, F.G., Baydar, H., Empirical Models Likely to be Used to Estimate the Evapotranspiration of Oil Rose (Rosa damascena Mill.), Süleyman Demirel Üniversitesi Ziraat Fakültesi Dergisi, 12(1), 1-10,2017.

[22] Kişi, Ö., Comparison of Different Empirical Methods for Estimating Daily Reference Evapotranspiration in Mediterranen Climate, Journal of Irrigation and Drainage Engineering, 140 (1), 04013002, 2014.

[23] Zhang, K., Kimball, J.S., Nemani, R.R., Running, S.W., A Continuous SatelliteDerived Global Record of Land Surface Evapotranspiration from 1983 to 2006 . Water Resour. Res., 46, W09522, 2010.

[24] Aksu, H., Arıkan, A., Satellite-based Estimation of Actual Evapotranspiration in the Büyük Menderes Basin, Turkey. Hydrology Research, 48(2), 559-570, 2017. 
[25] Peng, J., Loew, A., Chen, X., Ma, Y., Su, Z., Comparison of Satellite-Based Evapotranspiration Estimates over the Tibetan Plateau. Hydrol. Earth Syst. Sci., 20, 3167-3182, 2016.

[26] Citakoglu, H., Cobaner, M., Haktanir, T., Kisi, O., Estimation of Monthly Mean Reference Evapotranspiration in Turkey. Water Resour. Management, 28, 99-113, 2014.

[27] Falamarzi, Y., Palizdan, N., Huang, Y.F., Lee, T.S., Estimating Evapotranspiration from Temperature and Wind Speed Data using Artificial and Wavelet Neural Networks (WNNs). Agricultural Water Management, 140 (C), 26-36, 2014.

[28] Partal, T., Comparison of Wavelet Based Hybrid Models for Daily Evapotranspiration Estimation using Meteorological Data. KSCE Journal of Civil Engineering, 20 (5), 2050-2058, 2016.

[29] Yılmaz, S., Havza Koruma Eylem Planlarının Hazırlanması Projesi Konya Kapalı Havzası, 5098115-ÇE.10.49, TÜBİTAK Marmara Araştırma Merkezi Çevre Enstitüsü, 2010.

[30] Berke, M.Ö., Dıvrak, B.B., Sarısoy, H.D., Konya'da Suyun Bugünü Raporu,. WWF Türkiye, 2014.

[31] Blaney, H.F., Criddle, W.D., Determining Consumptive Use and Irrigation Water Requirements. Agricultural Research Service, Tech. Bull., 1275, 1962.

[32] Subedi, A., Chavez, J.L., Crop Evapotranspiration (ET) Estimation Models: A Review and Discussion of the Applicability and Limitations of ET Methods. Journal of Agricultural Science, 7 (6), 50-68, 2015.

[33] Jensen, M.E., Historical Evaluation of ET Estimating Methods. CSU/ARS Evapotranspiration Workshop, Fort Collins, CO, 12 March 2010.

[34] Vanderkimpen P. J., Estimation of Crop Evapotranspiration by Means of the PenmanMonteith Equation. PhD Thesis, Utah State University, Logan, Utah, 1991.

[35] Makkink, G.F., Testing the Penman Formula by means of Lysimeters. J Inst. Water Eng. 11(3), 277-288, 1957.

[36] Turc, L., Water Requirements Assessment of Irrigation, Potential Evapotranspiration: Simplified and updated Climatic Formula. Annales Agronomiques, 12, 13-49, 1961.

[37] Dodds, P.E., Meyer, W.S., Barton, A., A Review of Methods to Estimate Irrigated Reference Crop Evapotranspiration Across Australia. CRC for Irrigation Futures Technical Report No. 04/05. 2005.

[38] Morton, F.I., Operational Estimates of Areal Evapotranspiration and Their Significance to the Science and Practice of Hydrology. Journal of Hydrology, 66, 1-76, 1983.

[39] Hargreaves, G.H., Moisture Availability and Crop Production. Transaction of the ASAE, 18(5), 980-984, 1975.

[40] Hargreaves, G.H., World Water for Agriculture. Agency for International Development, 177, 1977. 
[41] Hargreaves, G.H., Samani, Z.A., Estimation of Potential Evapotranspiration. J. Irrig. Drain. Eng., 108 (3), 225-230, 1982.

[42] Hargreaves, G.L., Water Requirements and Agricultural Benefits for the Senegal River Basin. Master Thesis, Utah State University, Logan, Utah, 1983.

[43] Hargreaves, G.H., Samani, Z.A., Reference Crop Evapotranspiration from Temperature. Appl. Eng. Agric., 1(2), 96-99, 1985.

[44] Hargreaves, G.H., Allen, R.G., History and Evaluation of Hargreaves Evapotranspiration Equation. J. Irrig. Drain. Eng., 129(1), 53-63, 2003.

[45] Wang, Y.M., Traore, S., Kerh, T., Determination of a Reference Model for Estimating Evapotranspiration in Burkina Faso. In Proceedings of the 6th WSEAS International Conference on Artificial Intelligence, Knowledge Engineering and Data Bases, Corfu Island, 16-19 Feb. 2007.

[46] George, B.A., Reddy, B.R.S., Raghuwanshi, N. S., Wallender, W.W., Decision Support System for Estimating Reference Evapotranspiration. J Irrig. Drain. Eng., 128 (1), 1$10,2002 \mathrm{a}$.

[47] Heydari, M.M., Tajamoli, A., Ghoreishi, S.H., Darbe-Esfahani, M.K., Gilasi, H., Evaluation and Calibration of Blaney- Criddle Equation for Estimating Reference Evapotranspiration in Semiarid and Arid Regions. Environ Earth Sci., 74, 4053-4063, 2015. 